\title{
Thwaites' Diagnostic Scoring and the Prediction of Tuberculous Meningitis
}

\author{
Mustafa Sunbul Aynur Atilla Saban Esen Cafer Eroglu \\ Hakan Leblebicioglu \\ Department of Clinical Microbiology and Infectious Diseases, Ondokuz Mayis University, School of Medicine, \\ Samsun, Turkey
}

\section{Key Words}

Thwaites' diagnostic score - Tuberculous meningitis ·

Viral meningitis

\begin{abstract}
Objective: This study was conducted to investigate the applicability of Thwaites' diagnostic criteria in order to differentiate tuberculous from bacterial meningitis. Material and Methods: The study was done retrospectively in HIV-negative patients $(n=126)$ with meningitis. Of the 126 patients, 103 had bacterial meningitis and 23 patients had tuberculous meningitis. The diagnosis was confirmed microbiologically in 59 and 12 patients with bacterial and tuberculous meningitis, respectively. The prediction of tuberculous meningitis was determined by Thwaites' diagnostic scoring using parameters such as age, history of illness, white blood cell count, total cerebrospinal fluid (CSF) white cell count and the percent of neutrophils in CSF. The diagnostic value of the model was assessed by calculating the area under the receiver operating characteristic (ROC) curves. Results: The sensitivity and the specificity of Thwaites' diagnostic scoring were $95.6 \%(22 / 23)$ and $70.8 \%(73 / 103)$, respectively. In microbiologically proven cases the sensitivity and the specificity were $91.7 \%$ (11/12), $79.7 \%$ (57/59), respectively. The area under the ROC curve value for the diagnos-
\end{abstract}

tic scoring was 0.92. Conclusions: Thwaites' diagnostic score was found to be helpful in differential diagnosis of tuberculous meningitis, however, the usefulness of diagnostic scoring should be validated in large series especially in patients with viral meningitis and low CSF glucose levels.

Copyright (c) 2005 S. Karger AG, Basel

\section{Introduction}

Although antibiotics were invented more than 50 years ago, meningitis still continues to be a significant cause of morbidity and mortality [1]. Therefore a rapid and accurate clinical evaluation is needed for the determination of risks due to meningitis [2]. Examination of cerebrospinal fluid (CSF) is an important diagnostic tool. Isolation of a microorganism from a CSF culture is essential in the diagnosis, however, practically, this is impossible for each case [3]. Mortality rates are approximately $25-30 \%$ in acquired bacterial meningitis despite appropriate antibiotic therapy [4]. Recent studies indicate that delay in the diagnosis and treatment is a main factor associated with higher mortality rates [5]. This study was conducted to evaluate the applicability of the diagnostic criteria of Thwaites et al. [5] in order to differentiate tuberculous from bacterial meningitis.

\section{KARGER}

Fax +4161306 1234 E-Mail karger@karger.ch www.karger.com 
Table 1. Diagnostic criteria for tuberculous and bacterial meningitis

\begin{tabular}{|c|c|}
\hline Tuberculous meningitis & Bacterial meningitis \\
\hline M. tuberculosis isolated from CSF or & Pathogenic bacteria isolated from CSF or \\
\hline Clinical meningitis with negative Gram and India ink stains, & Clinical meningitis with all of the following: \\
\hline plus sterile bacterial and fungal culture, plus one or more of & Lymphocytes and neutrophils in CSF \\
\hline the following: & Low concentration of glucose in CSF \\
\hline Cranial CT scan consistent with tuberculous meningitis & $(<50 \%$ of that in blood $)$ \\
\hline (hydrocephalus, edema, basal meningeal enhancement) & Sterile blood and CSF \\
\hline $\begin{array}{l}\text { Chest radiograph consistent with active pulmonary } \\
\text { tuberculosis }\end{array}$ & $\begin{array}{l}\text { Full recovery (without antituberculosis } \\
\text { chemotherapy) } 3 \text { months after admission }\end{array}$ \\
\hline Good response to antituberculosis chemotherapy & \\
\hline
\end{tabular}

Table 2. Weighted DI scores for dichotomized clinical variables used for diagnostic rule in admission

\begin{tabular}{lc}
\hline Parameters & DI \\
\hline $\begin{array}{l}\text { Age, years } \\
\quad \geq 35\end{array}$ & \\
$\quad<35$ & 2 \\
Blood WBC, $10^{3} / \mathrm{ml}$ & 0 \\
$\quad \geq 15,000$ & \\
$\quad<15,000$ & 4 \\
History of illness, days & 0 \\
$\quad \geq 6$ & \\
$\quad<6$ & -5 \\
CSF total WBC, $10^{3} / \mathrm{ml}$ & 0 \\
$\quad \geq 900$ & 3 \\
$\quad<900$ & 0 \\
CSF $\%$ neutrophils & \\
$\quad \geq 75$ & 4 \\
$\quad<75$ & 0 \\
\hline
\end{tabular}

\section{Subjects and Methods}

This study was done retrospectively in adult patients admitted to the Department of Clinical Microbiology and Infectious Diseases, Ondokuz Mayis University School of Medicine, Samsun, Turkey. A total of $126 \mathrm{HIV}$-negative patients were included. Of these, 103 were diagnosed with acute bacterial meningitis, and 23 with tuberculous meningitis. A lumbar punction was performed routinely if not contraindicated. Characteristics like appearance, pressure, cell count per milliliter, protein and glucose levels were evaluated in CSF samples. CSF samples were stained with Gram, Ehrlich-Ziehl-Neelsen (EZN) and India ink stains. Samples were cultured on blood and chocolate agars and Löwenstein-Jensen medium. The diagnosis was confirmed microbiologically in 59 and 12 patients with bacterial and tuberculous meningitis, respectively. Differential diagnosis of tuberculous and bacterial meningitis was performed according to published criteria [5] (table 1).
The prediction of tuberculous meningitis was determined by Thwaites' diagnostic scoring using parameters such as age, history of illness, white blood cell count (WBC), total CSF white cell count and the percent of neutrophils in CSF. The diagnostic index for each of the five variables is shown in table 2 [5].

The total diagnostic index (DI) was calculated for each patient according to the formula: DI (age) + DI (blood WBC) + DI (history of illness) + DI (CSF white cell count) + DI (CSF \% neutrophils). As Thwaites et al. [5] stated the three points close to the top lefthand corner of the curve correspond to cutoffs of 4,3 , or 2 . Patients with DI scores $\leq 4$ are classified as having tuberculous meningitis while those with DI scores $>4$ are classified as having a version of bacterial meningitis.

Data were analyzed in SPSS for Windows version 10.0. The diagnostic value of the model was assessed by calculating the area under the receiver operating characteristic (ROC) curves.

\section{Results}

The clinical and laboratory findings in the 126 patients at first admissions are shown in table 3 . The sensitivity and the specificity of the Thwaites' diagnostic scoring for prediction of tuberculous meningitis in patients with clinical meningitis were $95.8 \%(23 / 24)$ and $71.6 \%(73 / 102)$, respectively. In microbiologically proven cases the sensitivity and the specificity were $91.7 \%(11 / 12), 79.7 \%$ (57/59), respectively.

Mycobacterium tuberculosis was isolated in 12 of 23 patients with tuberculous meningitis (52.1\%) on Löwenstein-Jensen or Bactec media. In 103 patients with acute bacterial meningitis, responsible pathogens were identified in $43(41.7 \%$ ) (Streptococcus pneumoniae in 25, Staphylococcus aureus in 7, other Streptococcus spp in 5, Neisseria meningitidis in 4 and Gram-negative bacillus in 3). The optimum cutoff for the total DI was found with the use of an ROC curve. The area under the ROC curve value for the diagnostic scoring was 0.92 (fig. 1). 


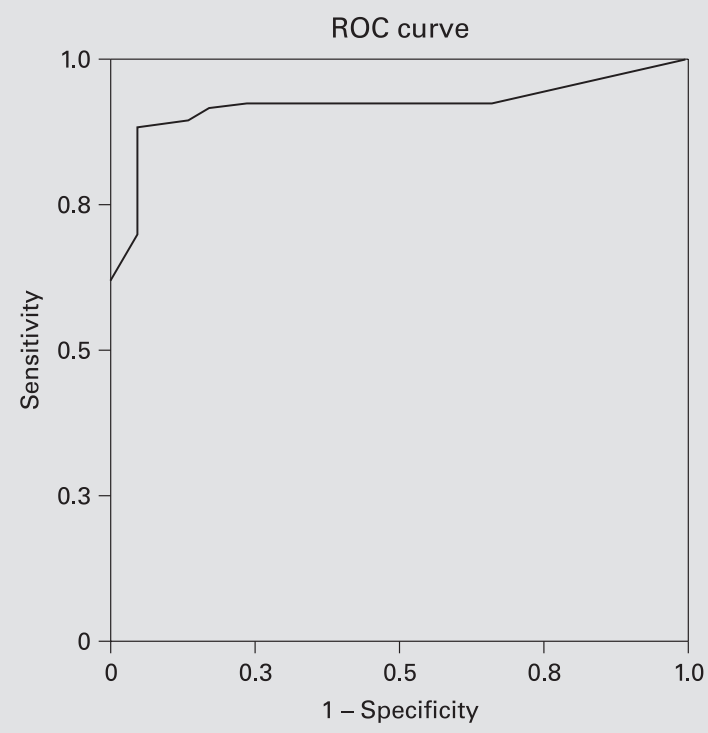

Fig. 1. ROC curve for prognostic index.

\section{Discussion}

The detection of microorganisms in CSF samples by either microscopy or culture and the prediction of antibiotic susceptibility is very important in the management of meningitis. However, these studies are not accomplished routinely. Besides, culture applications are timeconsuming in tuberculous meningitis and early diagnosis is hard to establish. Therefore, epidemiological data, pathogenesis and clinical findings must be assessed cautiously in the earlier course of the disease in patients with meningitis [6].

Our study revealed that neck stiffness is a common finding in meningitis, but it does not differentiate bacterial from tuberculous meningitis. On the other hand, tuberculous meningitis must be kept in mind particularly, if the disease course is longer than usual and the cranial nerve paralysis exists. Leukocytosis and an increase in neutrophil count in CSF indicate bacterial meningitis.
Table 3. Clinical and laboratory findings in patients with acute bacterial and tuberculous meningitis

\begin{tabular}{|c|c|c|c|}
\hline Parameters & $\begin{array}{l}\text { Tuberculous } \\
\text { meningitis }(n=23)\end{array}$ & $\begin{array}{l}\text { Bacterial } \\
\text { meningitis }(n=103)\end{array}$ & $\mathrm{p}$ value \\
\hline Age, years & 42.9 & 41.0 & 0.5 \\
\hline Range & $18-76$ & $16-99$ & \\
\hline Male/female & $6 / 17$ & $67 / 36$ & \\
\hline Fever, ${ }^{\circ} \mathrm{C}$ & $37.2 \pm 0.2$ & $37.4 \pm 0.1)$ & 0.5 \\
\hline Headache & $21(91.3 \%)$ & $84(81.5 \%)$ & 0.25 \\
\hline Duration of illness & $15.04 \pm 1.9$ & $3.85 \pm 0.3$ & $\mathrm{p}<0.001$ \\
\hline Neck stiffness & $22(95.6 \%)$ & $93(90.2 \%)$ & 0.7 \\
\hline \multicolumn{4}{|l|}{ Consciousness } \\
\hline Conscious & $1(4.3 \%)$ & $28(27.2 \%)$ & - \\
\hline Sleepy & $5(17.5 \%)$ & $17(16.5 \%)$ & - \\
\hline Somnolence & $9(39.1 \%)$ & $43(41.7 \%)$ & - \\
\hline Coma & $8(34.8 \%)$ & $15(14.6 \%)$ & - \\
\hline Hemiplegia & $3(13.0 \%)$ & $12(11.7 \%)$ & 1.0 \\
\hline Cranial nerve palsies & $9(39.1 \%)$ & $9(8.7 \%)$ & 0.001 \\
\hline WBC count, $\times 10^{3} / \mathrm{ml}$ & $10,572 \pm 907.6$ & $17,176 \pm 896.8$ & $\mathrm{p}<0.001$ \\
\hline$\%$ neutrophils & $78.3 \pm 4.0$ & $82.2 \pm 1.0$ & 0.5 \\
\hline Sedimentation rate, $h$ & $35.2 \pm 5.0$ & $61.1 \pm 3.3$ & $\mathrm{p}<0.001$ \\
\hline \multicolumn{4}{|l|}{ Appearance of CSF } \\
\hline Clear & $15(62.8 \%)$ & $15(14.7 \%)$ & - \\
\hline Purulent & - & $73(71.6 \%)$ & - \\
\hline Xanthochromic & $8(37.2 \%)$ & $12(11.8 \%)$ & - \\
\hline $\mathrm{CSF}$ total $\mathrm{WBC}, \times 10^{3} / \mathrm{ml}$ & $286 \pm 44.2$ & $5,449 \pm 1,300$ & 0.05 \\
\hline CSF \% neutrophils & $30.9 \pm 5.9$ & $81.9 \pm 2.5$ & $\mathrm{p}<0.001$ \\
\hline CSF/blood glucose & $0.24 \%$ & $0.24 \%$ & 0.5 \\
\hline CSF protein, g/dl & $291 \pm 45.6$ & $373 \pm 29.9$ & 0.1 \\
\hline EZN/Gram stain positivity & $3(13.0 \%)$ & $65(65.7 \%)$ & - \\
\hline Culture positivity & $12(52.1 \%)$ & $43(41.7 \%)$ & - \\
\hline
\end{tabular}

Mean \pm standard error of the mean (SEM). 
Laboratory parameters like total $\mathrm{WBC}$ in $\mathrm{CSF}, \mathrm{CSF} /$ blood glucose ratio and protein level in CSF were found to show no significant differences in tuberculous and bacterial meningitis.

When the diagnostic score of Thwaites et al. [5] was applied to our patients with clinical meningitis, the sensitivity and specificity for prediction of tuberculous meningitis were 95.8 and $71.6 \%$, respectively, but for patients with positive bacterial result confirmed by microscopy and/or culture evidence of bacteria in CSF the predictive values for sensitivity and specificity were 91.7 and $79.7 \%$, respectively, thereby making Thawaite's diagnostic scor- ing a useful technique for differential diagnosis of tuberculosis meningitis, but we suggest that the usefulness of the diagnostic scoring should be validated in large series especially in patients with viral meningitis and low CSF glucose levels.

\section{Conclusion}

The results show that the Thwaites' diagnostic score is helpful in differentiating tuberculous from bacterial meningitis.

\section{References}

1 Quagliarello V, Scheld WM: Bacterial meningitis: Pathogenesis, pathophysiology, and progress. N Engl J Med 1992;17;327:864-872.

2 Aronin SI: Bacterial meningitis: Principles and practical aspects of therapy. Curr Infect Dis Rep 2000;2:337-344.

-3 Sinner SW, Tunkel AR: Approach to the diagnosis and management of tuberculous meningitis. Curr Infect Dis Rep 2002;4:324-331.

4 Thomas KE, Hasbun R, Jekel J, Quagliarello VJ: The diagnostic accuracy of Kernig's sign, Brudzinski's sign, and nuchal rigidity in adults with suspected meningitis. Clin Infect Dis 2002;35:46-52.
5 Thwaites GE, Chau TTH, Stepniewska K, Phu NH, Chuong LV, Sinh DX, White NJ, Parry CM, Farrar JJ: Diagnosis of adult tuberculous meningitis by use of clinical and laboratory features. Lancet 2002;360:1287-1292.

6 Weinstein L: Bacterial meningitis: Specific etiologic diagnosis on the basis of distinctive epidemiologic, pathogenetic, and clinical features. Med Clin North Am 1985;69:219-229. 